\title{
Analyzing the urban heat island characteristics and mitigation strategies in eight arid and semi-arid cities
}

\section{Abstract}

The aim of the study is two folds: first, the study analyze the formation of the Urban Heat Island (UHI) in eight different cities in arid and semi-arid region. The analysis is based on land cover / land use (LCLU) classification (urban, green, and bare areas). Second, the study synthesize the mitigation strategies to reduce the land surface temperature (LST) and hence the UHI effects in the arid and semi-arid cities. The study found that the bare areas has the highest mean LST compared to the urban and green areas. Furthermore, the study found that the LST varies in each of the LCLU categories and hence some areas of the three categories have LST lower or higher than the other categories and hence not always one category has the highest LST compared to the other categories. The outcomes of this study may have key implications for urban planners seeking to mitigate urban heat island effects in arid and semi-arid urban areas.

\section{Introduction}

UHI is a phenomenon develop when the surface and atmospheric temperatures in an urban area are noticeably warmer than their neighboring non-urbanized areas that directly surround it as a result of the increase in the heat storage capacity of urban surfaces. This variation in temperature is what constitute the UHI effect. Different studies have found that UHI can increase air temperature in urban areas between $2^{\circ} \mathrm{C}$ and $15^{\circ} \mathrm{C}$. In arid and semi-arid regions, the temperature in the centers of the urban areas increase within the range of $2^{\circ} \mathrm{C}-4^{\circ} \mathrm{C}$ when compared to their surroundings. The spatial pattern of UHI in the urban areas reflect the different nature of their components and aggravating factors. One main reason causing this phenomenon is human activities in creating dense built-up areas, which produce excess heat energy that are captured in the UHI during the daytime and diffused at night.

\section{Study area}

The Gulf Region is characterized by being an arid and semi-arid climate zones, as the climate is extremely hot in the summer and moderate in the winter. Furthermore, the relative humidity is high, and rainfall is low and irregular. Hitherto, few studies have investigated the UHI within arid and semi-arid regions. As urbanization is projected to be high, sustainable planning of built-up environment to mitigate UHI effects presents an urgent need for immediate attention. This becomes more significant when considering climate change effects.

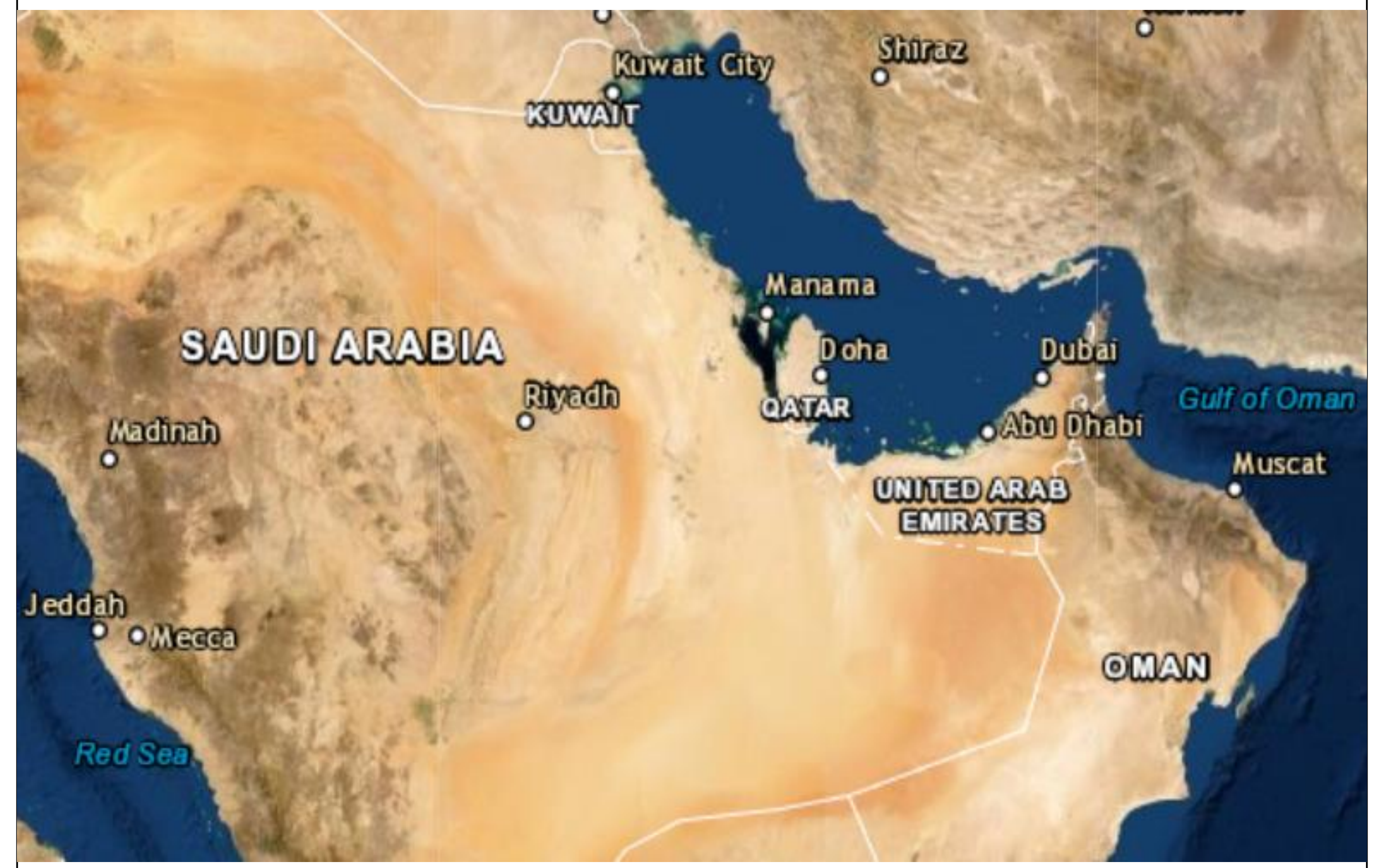

Figure 1: The study area. Source: Earthexplorer.usgs.gov

The study investigates how the thermal behaviour is affected by urbanization and population growth. The LSTs and normalized difference vegetation index (NDVI) were retrieved from remote sensing images. In this study, Spatial and temporal LST is extracted in three phases e.g. in 1990, 2000, and 2018 and were analyzed for the spatial distribution of changes in temperature and LCLU using Landsat images. For each city, LST, NDVI, and urban areas have been analyzed. The main focus is placed on the summer period.

\section{Methodology}

This study uses remote sensing and GIS for comparative assessment of LST in eight cities in an arid and semi-arid climate region. The study utilized multi-spatial and multitemporal satellite data acquired from Landsat 5 Thematic Mapper (TM) (1990, 2000), and Landsat 8 Operational Land Imager (OLI) (2018). LST was derived from Landsat 8 and Landsat 5. In Landsat 8, bands 10 and 11 were used, while band 6 was used in Landsat 5 . The images used in the study for the eight cities are freely accessible images processed by NASA and were corrected for radiometric and geometrical errors (level-1 products http://earthexplorer.usgs.gov/). The classification method was developed using a combination of data collected from the satellite imagery and ArcGIS software. Three land cover classes were found occurring within the study area. Normalized difference built-up index (NDBI), NDVI, and LST values were extracted from each pixel in the study area for each point data type. Linear regression analysis were applied to determine the correlation between LST and land cover type. The NDBI, NDVI, and the bare area are the input for the linear regression model.

\section{Results and discussion}

UHIs spatial patterns and temporal variations

The spatial distribution of the LST values at different LCLU classes were calculated and mapped for each of the eight cities using remote sensing technology and satellite imagery to show the differences of temperature and hence the areas influenced by UHI for the years 1990, 2000, and 2018 as shown in Figure 2.

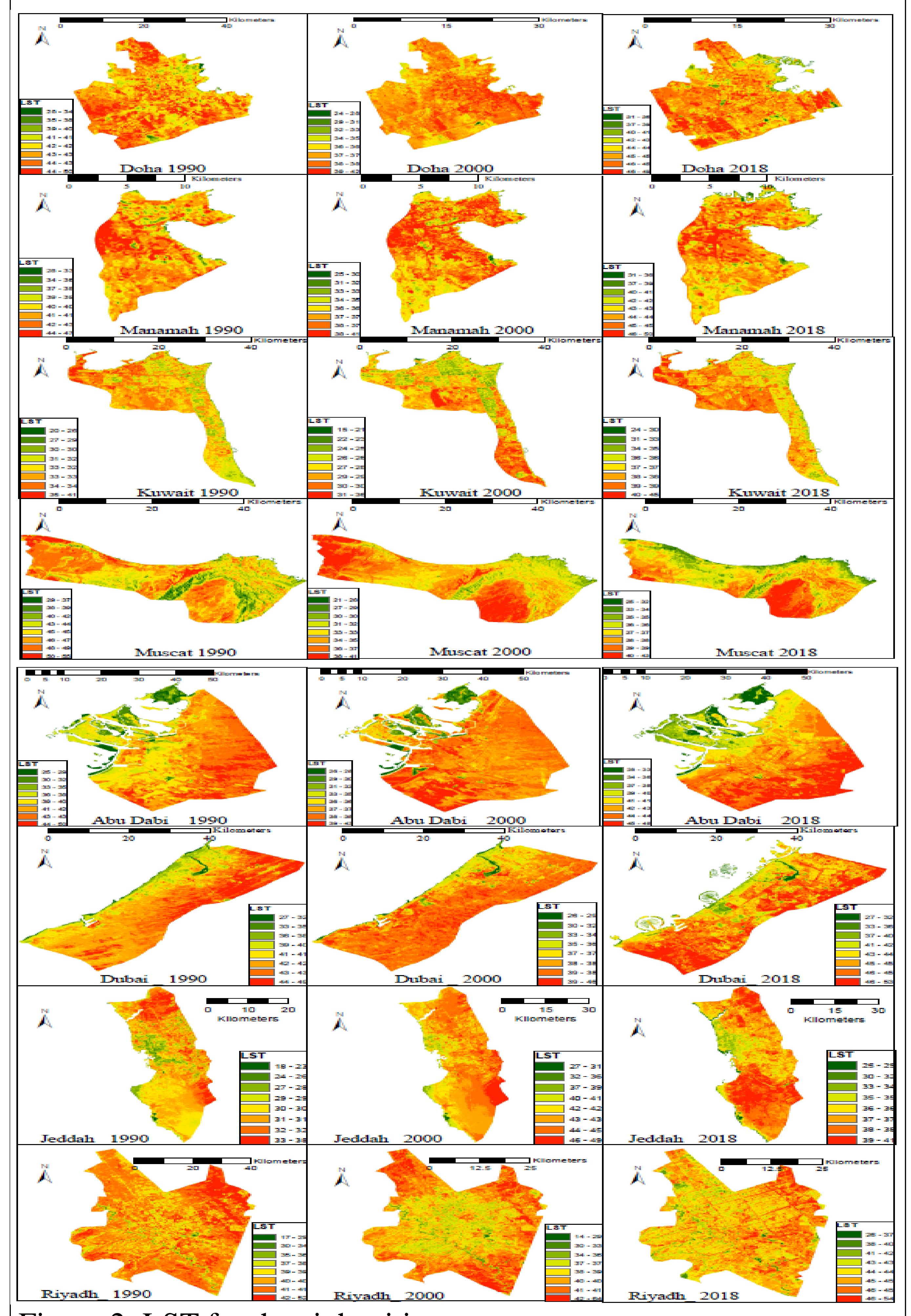

Figure 2: LST for the eight cities

Green areas have the lowest mean LST followed by the urban areas, while the bare areas have the highest mean LST (Table 2) revealing the role of LCLU in LST values. This indicates the inversion of UHI phenomenon in these cities as sand constitute the main bare surface and hence absorb more sun light than urban or green areas due to their low reflectivity.

Table: Mean surface temperature $\left({ }^{0} \mathrm{C}\right)$ in the eight cities

\begin{tabular}{|c|c|c|c|c|c|c|c|c|c|}
\hline \multirow[t]{2}{*}{ City } & \multicolumn{3}{|c|}{1990} & \multicolumn{3}{|c|}{2000} & \multicolumn{3}{|c|}{2018} \\
\hline & $\begin{array}{c}\text { Urban } \\
\text { area }\end{array}$ & $\begin{array}{c}\text { Green } \\
\text { area }\end{array}$ & $\begin{array}{l}\text { Bare } \\
\text { area }\end{array}$ & $\begin{array}{c}\text { Urban } \\
\text { area }\end{array}$ & $\begin{array}{c}\text { Green } \\
\text { area }\end{array}$ & $\begin{array}{l}\text { Bare } \\
\text { area }\end{array}$ & $\begin{array}{c}\text { Urban } \\
\text { area }\end{array}$ & $\begin{array}{c}\text { Green } \\
\text { area }\end{array}$ & $\begin{array}{l}\text { Bare } \\
\text { area }\end{array}$ \\
\hline Abu Dhabi & 42 & 37 & 43 & 36 & 34 & 38 & 41 & 37 & 44 \\
\hline Dubai & 42 & 41 & 44 & 36 & 34 & 38 & 40 & 39 & 42 \\
\hline Jeddah & 29 & 28 & 31 & 41 & 40 & 43 & 36 & 33 & 37 \\
\hline Riyadh & 39 & 37 & 40 & 38 & 34 & 39 & 44 & 43 & 44 \\
\hline Doha & 41 & 40 & 42 & 37 & 36 & 37 & 43 & 41 & 44 \\
\hline Manamah & 41 & 40 & 42 & 37 & 35 & 37 & 43 & 41 & 44 \\
\hline Kuwait & 31 & 29 & 32 & 27 & 26 & 28 & 37 & 36 & 38 \\
\hline Muscat & 44 & 43 & 45 & 33 & 30 & 34 & 36 & 34 & 37 \\
\hline
\end{tabular}

Results and discussion The variation in the mean LST between the three types of land cover varies among most of the eight cities and over time as shown in the table.
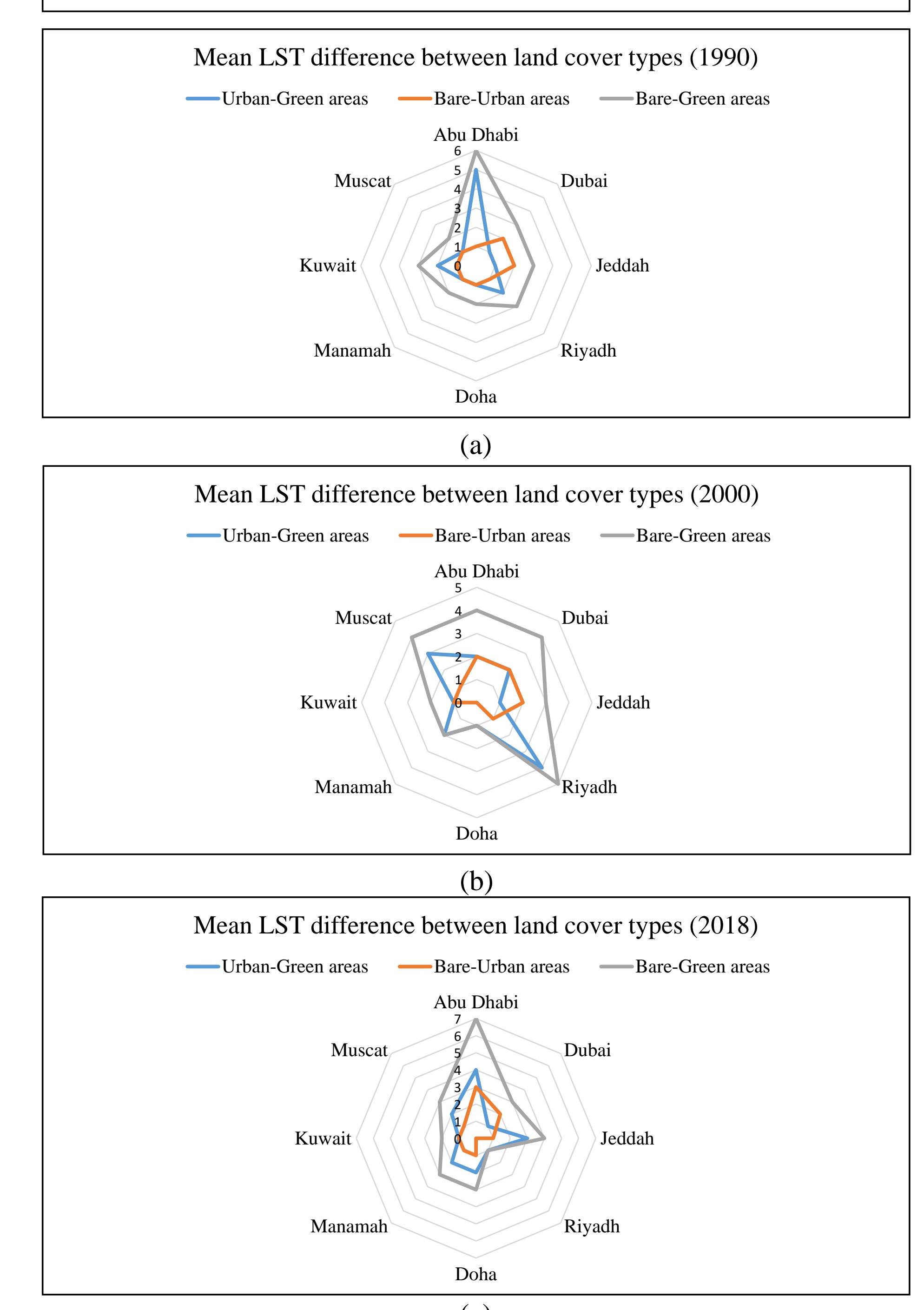

Figure 3: Temperature $\left.{ }^{\circ} \mathrm{C}\right)$
(a) 1990, (b) 2000, (c) 2018

The impact of urban areas on LST in arid and semi-arid region

The relationship between the LST and the NDBI is presented in a twodimensional scatter plot as shown in Figure 4. This relationship is based on intersecting the NDBI map with the LST map using GIS software. The figure shows that the LST of the urban areas is not homogenous but it varies within each city, as there is a high range between the minimum and maximum temperature as shown in Figure 4. This variation depends on the characteristics of the urban location.

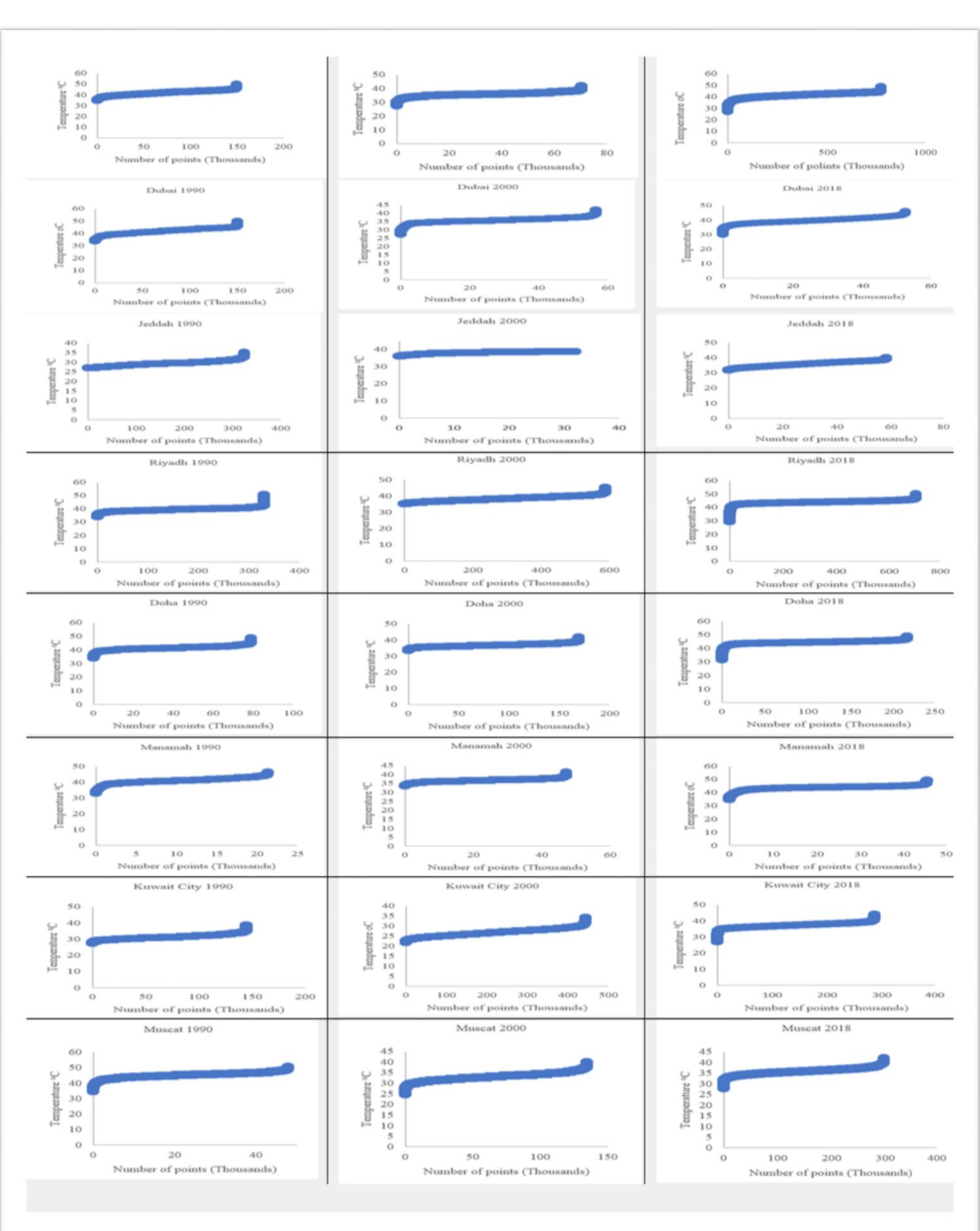

Figure 4: LST of urban area

Planning for mitigating UHI in arid and semiarid cities

A variety of strategies and techniques had been proposed, recommended, and implemented in varies cities to counterbalance the impact of UHI effects and to moderate temperatures and elevate the adaptive capacity of urban areas to the warming climate. Based on the literature, the mitigation strategies of UHI effects in arid and semi-arid regions can be grouped into five categories:

1. Increase solar reflectance strategies,

2. Land scape and land use planning (urban design and urban infrastructure related strategies),

3. Paved surface

4. Anthropogenic heat related strategies

. Greening strategies (parks, green roofs, green facades and walls). 